\title{
Linguo-pragmatic potential of creolized texts in online international EFL exams
}

\author{
Victoria Malakhova ${ }^{1 *}$, and Ekaterina Kopshukova ${ }^{2}$ \\ ${ }^{1}$ Moscow State Institute of International Relations (University) of the Ministry of Foreign Affairs of \\ the Russian Federation, Moscow, Russian Federation \\ ${ }^{2}$ Samara National Research University, Samara, Russian Federation
}

\begin{abstract}
Nowadays we face the intense transition of the modern education system into the digital space due to some important reasons, the main of which are development of information technologies and the environmental factor. As a result, the priority is given to online exams; this requires both the content and design of exam materials to be adapted to the demands of the modern life and business world. In this connection, the analysis of creolized international EFL exam texts becomes relevant. The study sets its purpose the systematization and description of the main verbal and non-verbal markers of minitexts from international ESL exam demo-papers, which reveal the pragmatic potential of the texts considered.

The research methodological background is a combination of structural, semantic, pragmatic and cognitive text analysis.

We analyze texts with full and partial creolization and signs focusing on paralinguistic means of enhancing the linguo-pragmatic potential of creolized international ESL exam texts. The study highlights the functions which are performed with the synthesis of verbal and nonverbal communicative means. The findings make a significant contribution to developing and improving the effectiveness of exam materials and the process of conducting online exams in English.
\end{abstract}

\section{Introduction}

Current requirements to fostering students' intercultural communicative competence make the modernization of the education system indispensable and urgent. Due to this, the study of the academic discourse, and the English-language examination discourse in particular, is rather relevant. We face the necessity of search for new ways of developing the educational field, especially in the situation of online learning popularization. To our mind, the linguistic interpretation of texts of English-language demo papers of international exams is of great scientific interest, since it contributes to description of the features of the modern multicultural society in general. This can be explained through the social demand on texts compiling, according to which the society needs culturally erudite people who know the basics of everyday and business communication in English.

The findings obtained deepen the knowledge about the system of markers revealing the behavioral patterns and peculiarities of the mentality of members of the English-speaking society, which can help those who study English as a foreign language. In our opinion, the text component of demo papers of English-language examination materials is a system of meanings of the English-language academic discourse; such meanings are formed by

\footnotetext{
*Corresponding author: v.l.malakhova@inno.mgimo.ru
} 
linguistic and extra-linguistic means and socio-cultural codes. Demo paper texts reflect social practice from various fields of human life, socio-cultural values and traditions, and create new models of social experience as a result of people's cognitive and communicative activity.

Expansion of online learning leads to the need of examination procedure optimization. Since the time of examinations is strictly restricted, reading materials have to be of reduced format. In this case, a high potential belongs to creolized minitexts of the English-language international exams, which make it possible to speed up the perception of information due to the graphic component. However, it is worth mentioning that examination texts require constant updating. This means that the effective work with such texts requires a modern and scientifically sound mechanism.

Taking into account everything said above, we can state the relevance of the analysis of creolized international EFL exam texts. As the main goal of the research we set identification and systematization of the verbal and non-verbal markers of minitexts from international ESL exam demo papers, which reveal the pragmatic potential of the texts under consideration.

\section{Background and method}

For our research of creolized texts, their functions and role in online examination materials, we used minitexts (up to 900 words) from demos of British Certified English Examinations (ESOL), namely: YLE (Starters, Movers, Flyers), A2 Key (KET), A2 Key for Schools (KET), B1 Preliminary (PET), B1 Preliminary for Schools (PET), B2 First (FCE), B2 First for Schools (FCE), Skills for Life, C1 Advanced (CAE), C2 Proficiency (CPE), IELTS; PTE Young Learners, PTE General, PTE Academic; City \& Guilds exams; ESOL (Skills for Life), ESOL for Schools; Integrated Skills in English, ESOL for Life; JETSET; TOEIC, TOEIC Bridge; DipTrans; ESB ESOL for Work; и IDBC. All materials have an open access on the official websites of leading international organizations having the right of issuing international certificates after successful passing of the English exam: University of Cambridge, City \& Guilds, London Chamber of Commerce and Industry (LCCI), Pearson Education и Pearson Edexcel, Trinity College London, Educational Testing Service (ETS), English Speaking Board International Ltd (ESB) The Chartered Institute of Linguists.

To form the theoretical basis of the research, we analyzed the works on problems of linguopragmatic analysis [1], cultural linguistics [2], discourse analysis [3, 4], discourses interferences [5], intertextuality [6], computer-mediated communication [7, 8], minitexts [9] and creolized texts [10-12].

For the analysis of the linguistic material of creolized texts, we have applied a complex and integrated approach combining structural, semantic, pragmatic, cognitive and linguistic synergy methods. This helps us state that the compositional, structural and semantic parameters of texts affect the formation and evolution of the creolized text space of the English-language academic discourse.

\section{Results}

The analysis of the linguistic and iconic components of texts with full and partial creolization contributes to specifying their degree of involvement in the formation of the creolized text space of the English-language academic discourse. We can state the effectiveness of text creolization in the process of teaching English which can significantly motivate and encourage students, as well as form their tolerant and respectful relations in society.

We believe that the next stage of studying this problem implies the investigation of the high potential of creolized multimedia content as a more advanced and widespread type of creolized 
text. It is precisely its structure and didactic capabilities that significantly help developing students' intercultural communicative competence in the English teaching process. In our opinion, applying modern information and communication technologies can greatly improve the educational process organization and activate the cognitive activity of students.

\section{Discussion}

\subsection{The academic discourse as a multidisciplinary foundation for creolized texts}

Human activities forming and reproducing meaning are highly regulated by socio-cultural codes within history and traditions. And it is the academic discourse that operates on all these big data via cognitive and communicative tools; this helps accomplish the goal of regulating and transmitting certain knowledge, skills and abilities, values and behavioral patterns [13]. Modern academic discourse is definitely unique because it can be characterized by the duality of the whole information world within its boundaries. It turns out that the academic discourse combines infosphere and intertext, i.e. educational, social, cultural texts, as well as scientific and technical texts from the world of national and transnational systems [14]. A distinguishing feature of the academic discourse is its adaptability to rapid changes in the external world and new standards.

We consider the certified examination format to be an academic discourse component. This format can be described as a separate and holistic system which is open and capable of self-organization due to inevitable dynamic transformations [15]. The self-organization process of this system are observed after analyzing particular cognitive and communicative means from the set of creolized texts in ESL exam demo papers offered to potential candidates who do their best to revise for the British Certified English exams.

Also examination materials include creolized texts which make an applicant deal with some modeled environment referred to the situations that are thematically different from the educational ones. Therefore, the organization of examination materials in terms of discourse is affected as well. For instance, there are some lexical and grammatical, morphological and syntactic markers characterizing a particular type of discourse. Thus, on the one hand, the academic discourse is unique as it has to select, combine, keep and operate creolized texts with their own specific features from different sources, but on the other, the academic discourse actualizes other types of discourse, because of transmitting their particular sets of discourse markers. So, the academic discourse may unite texts of the socio-cultural and humanitarian discourse; natural (mathematical), empirical (physics, biology) and formal (logic) sciences discourse. For example, when getting prepared for IELTS candidates may study popular scientific texts in philology (A Silent Force), ecology (The Truth about the Environment), psychology (Obsessive-compulsive Disorder), biology (Antarctic Penguins), etc.

Even though working with ESL demo papers which include creolized texts of such a disciplinary and normative field which the candidate does not belong to, they become dependent on the representation and interpretation of these texts by the addressee (a group of authors who compile exam materials). Moreover, as a candidate may not be aware of the topic of the text, the academic discourse has to adapt the materials from other types of discourse in order to attract the applicant's educational and cognitive interest in the relevant but unfamiliar field of scientific knowledge.

This leads to several disputable questions. The first one is how to transform scientific knowledge in the academic discourse and to adapt the meaning of theoretical terms to the cognitive level of recipients with the corresponding level of education without losing the 
understanding of the information. The second question touches upon the role of verbal definitions in getting the meaning of the text by the recipients. The third point is a combination of eidetic (figurative and visual) and abstract components, intuitive and discursive (logical) components in knowledge representation. The fourth relevant problem is connected with the use of optimal argumentative procedures and interpretive models. The fifth question is to what extent the historical and theoretical content of knowledge can be combined. The sixth item open to discussion is interdisciplinary connections and ways to demonstrate them. Last but not least, there are socio-cultural, ethical and deontological features of the adaptable scientific knowledge that are to be taken into consideration.

Not only does the field of scientific knowledge interest the academic discourse, but also there is a great demand for international certificates in English that would confirm the applicant's ability to cope with typical situations from everyday life. As a result, the authors of exam materials try to meet the new demands of modern times and adapt the exam materials enriching them with creolized texts of an updated format - announcements, road signs, billboard, memos, application forms, booklets, brochures, questionnaires, etc. It is easily observed that those text fragments reflect various areas of human activity.

We have also revealed that the form of communication increasingly influences the processes which may take place in different literary languages. This may cause variability or even a change in the literary norm of traditional (oral and written) forms of communication and the culture of speech in general [7]. Moreover, computer based communication and the use of latest technologies, such as tablets and smart phones connected to the Internet, make applying different types of creolized texts, such as e-mails, chats, blogs or emails, more than relevant.

\subsection{Minitexts as a distinguishing feature of the academic discourse}

The modern academic discourse is characterized by a special type of texts known as minitexts which are distinguished with integrity, grammatical, semantic and logical coherence, semantic completeness and independence, conciseness, situational attachment, communicative and pragmatic functionality $[9,16]$. The analysis of texts from demo papers of certified ESL exams shows that most of them are of a creolized type. Creolized texts transmit some knowledge, content, or message. For the effective presentation of the message, authors and compilers have to thoroughly select minitexts out due to their communicative sense and informativity on the content of social, cultural and educational topics. For instance, minitexts about a healthy lifestyle - Fitness Center (IELTS), food Iced Coffee (Trinity, SFL, E2), How to make bread (Trinity), medical care - Bentley Hospital Catering Service (IELTS), employment - Looking for Work (IELTS), music Music to the Ears (IoL, DipTrans), cinema - The Early Cinema History (IELTS), etc can be considered as a vivid example of communication on a everyday social, cultural and educational topics.

Conveying of the message through a text and representing of the creolized minitext organization are reached with special discursive methods and certain structures. For successful examination, an applicant has to identify, comprehend and use them alongside with other linguistic means.

Remarkable is that, when taken out from the natural discursive context and placed in the academic discourse, modeled creolized minitexts lack or even lose the informative function, since the information in them stops being reliable. However, they still keep their social function, although without the appropriate situational context.

Our study allows us to state that creolized minitexts in ESL exam demo papers are very beneficial because the time for completing the tasks is strictly regulated by the format of the exam; moreover, the checking of the language knowledge with their help requires less 
manual processing, as a consequence financial costs are also lower. But what is more important, and what gives the leading status to creolized minitexts, is their close relation with the laws of linguosynergetics, since with a high degree of clarity creolized minitexts contribute to successful solution of the problem - to define the level of English proficiency from various human spheres in a limited period of time. In addition, creolized minitexts can be modified, updated and given some new cognitive component much more easily. Therefore, it can serve as a signal of the linguosynergetic potential of creolized minitexts.

\subsection{Specifics of fully and partially creolized texts of English-language international online exams}

As any other type of demo exam texts, creolized texts are characterized by the integrity of the compositional structure and distinguished by an average modeling of text fragments, standardized design, and repetitiveness of linguistic means. All these make such texts meet the requirements of modern English-language academic discourse.

We consider applying creolized texts in exam demos to be feasible as they successfully contribute to solving one of acute issues - in strictly restricted time period they can define the level of the student's knowledge of the English language in various spheres: social, cultural, educational, scientific, etc.

A distinguishing feature of texts of English-language international online exams which attracted our attention during the study is the wide-spread application of graphic images and various non-verbal means (such as pictures, photographs, drawings), as well as paralinguistic ones (for instance, font, color, text location). This promotes transmission and perception of high volume information. Thus, the formation of the textual space using creolized texts undoubtedly increases the role of visualized data. Such a form of text presentation

- helps the recipient quickly perceive the information due to the high speed of information transfer;

- $\quad$ ensures deep comprehension of the information presented;

- reduces the risk of communicative interference for adequate understanding.

Depending on the correlation between verbal and non-verbal means, creolized texts in demo papers of the English-language certified exams can be classified as texts with full and partial creolization.

As fully creolized texts we consider ones that may have a title but the plot is depicted in the pictures and does not have a verbal description. This type of text can be illustrated with demo papers of exams for children (Cambridge YLE, PTE Young Learners). Young applicants are invited to study the illustrations united by the single storyline. After analyzing them, the applicant completes one of the tasks based on the images, for example: Answer the questions, Multiple choice, Multiple matching. In this case, the verbal text of the assignment completely depends on the graphic chain which performs an informative function and is an obligatory text element. 


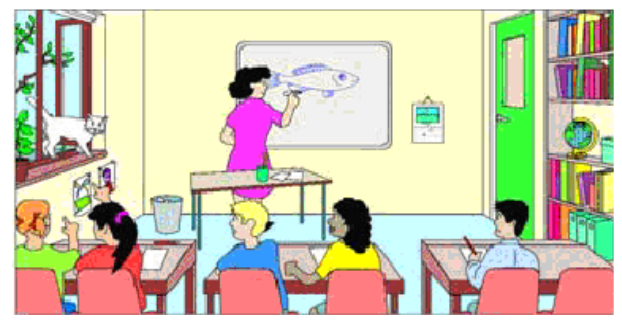

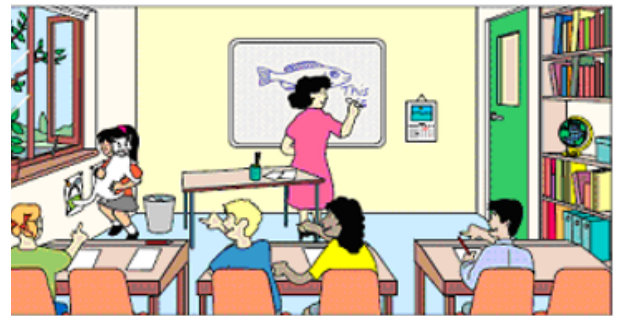

1. Who is writing on the board?

2. What is the girl at the window doing now?

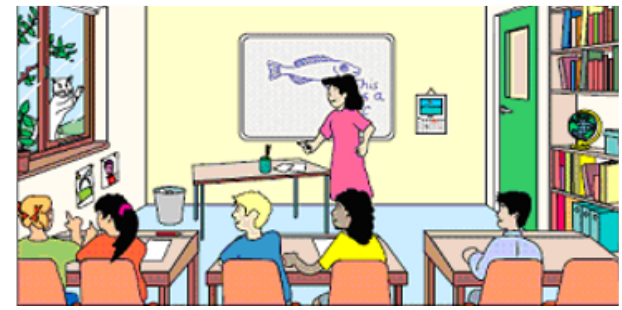

3. What is the teacher doing?

4. Who is pointing at the cat?

Fig. 1. Fully creolized text.

(Cambridge, YLE, Starters)

In the case of a contradiction between the graphic and verbal components in tasks such as True/False, Yes/No, a special type of relation arises between these two elements of the creolized text, which allows completing the task on the correct understanding of the verbal text and performs the verification function.

Look at the picture. Read the statements and write Yes or No for each of them.

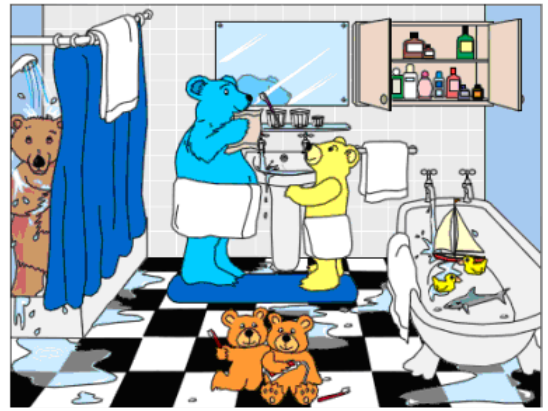

\section{Examples}

There are five bears in the bathroom.

The small yellow bear is taking a shower.

$\underline{Y e s}$

$\underline{N o}$

(Cambridge, YLE, Movers)

Fig. 2. Fully creolized text with contradicting graphic and verbal components.

The function of checking the understanding of verbal information is also performed by graphic images presenting, in fact, the answer options in Multiple choice or Multiple matching tasks when it is required to choose an illustration that matches the description in the text. As a rule, images contain objects recognizable to most students (for example, the sights of London); this implies their having the certain background knowledge. 
In contrast to the described texts with full creolization, in partially creolized texts, graphic images are smaller and have a non-fixed location. Thus, pictures and photographs can be found inside the text (on the left or on the right), in the assignment, and sometimes even after the text. In any case, they act as hints and give a first idea of the content of the verbal text before reading it. So, we can conclude that the non-verbal aspect of the creolized text has an introductory function, i.e. familiarizes the applicant with the content of the verbal text.

As an interesting example deserving special attention we consider creolized texts in which a graphic image is located before the verbal text without a heading. In this case, conforming to the principles of linguosynergetics, the non-verbal component replaces the heading and, therefore, fulfills its nominative function.

To a greater extent, illustrations perform a descriptive function, since the abundance of graphic images reflects a wide thematic variety of examination texts, contributes to the intensification of the cognitive activity of applicants and motivates them for the quick search for the required information in the verbal text when doing the task. At the same time, portraits or images of people may contain additional information that is not reflected in the verbal text. Thus, such items can be focused on as the appearance, nationality, gender characteristics. This helps determine the age and health condition; comprehend the interests or hobbies of the depicted person (for example, a musical instrument or sports equipment in the hands); specify the mood or character (for example, a tired or frightened face expression), etc. Images of this kind supplement the verbal text with new optional information, i.e. they perform both the descriptive and informative functions.

A number of tasks requires the ability of analyzing the information presented in diagrams and graphs with numerical data, geographical maps, city maps, etc (for instance, the names of streets and the location of buildings as a hint for setting up with the area). In this type of tasks, graphic images are to combine verbal and non-verbal elements of creolized texts as they fulfill an informative function.

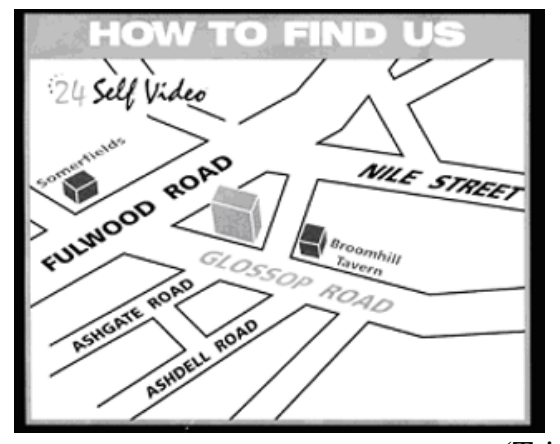

(Trinity, SFL, E3)

Fig. 3. Partially creolized text with informative function.

Very interesting, in our opinion, are examples when kind and funny graphic images perform an expressive function. As a rule, these are cute photographs and illustrations of humans and inhabitants of the animal world, charming children, and adults in a friendly environment. Usually this is not reflected at the linguistic level in the verbal aspect of the text. Due to such non-verbal means, one transfers the information about the necessity of the caring about animals, about the peaceful coexistence of wild animals and humans, about warm relations and understanding between representatives of various generations and so on. Moreover, in examination demo papers for children, illustrations are preaching in nature, as they warn children about the sad consequences of being too much playful, about the importance of observing hygiene rules and correct behavior in public places (for 
example, in a park, at a train station, etc). Thus, creolized texts carry out a socially regulating function. In the wording of test tasks, there can be a sample of the graphic answer option, which is to be inserted into the answer form. This will be a marker of the implementation of the organization and orientation function.

Answer:

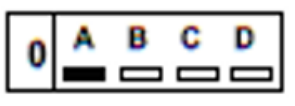

\section{(Cambridge, KET)}

Fig. 4. Partially creolized text with organization and orientation function.

\subsection{The role of paralinguistic means in forming creolized text space of EFL exams}

Along with a verbal component of both creolized and non-creolized texts, a high informative potential also belongs to paralinguistic means. In our study, we refer to them as a variety of fonts: upright and italic, bold and semibold, with various contrast, width, size and legibility. Different font parameters perform attractive and semantic-highlighting functions, which makes the verbal component easily distinguishable and readable from the screen. To imitate books and magazines, information plates, advertising signs and announcements, compilers of examination demos use a variety of title fonts, including poster and display fonts, as well as inscriptions in WordArt format. The choice of a suitable font style and type mostly depends on aesthetic and expressive functions.

To create the impression that the applicant deals with an authentic English text from a menu, newspaper, information plate, mail letter or poster, one uses spacing, line spacing and indentation, columns, numbered lines; this makes reading from the screen more convenient. A certain informative function is performed by the text in autoshapes, for example: a scroll, a document flowchart, a rounded rectangle, a wave, an oval, less often with colour options.

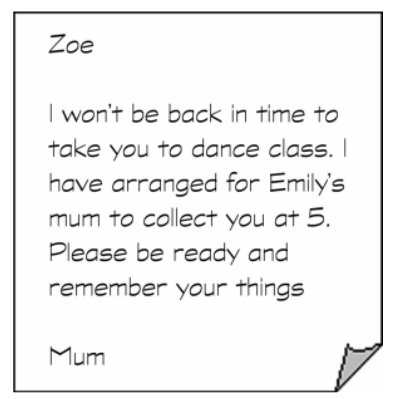

\section{Ford Focus \\ Good Condition \\ 1998 \\ MOT 6 months \\ $£ 500$ ono \\ Phone 26430921}

(Edexel, SET, E2, READING)

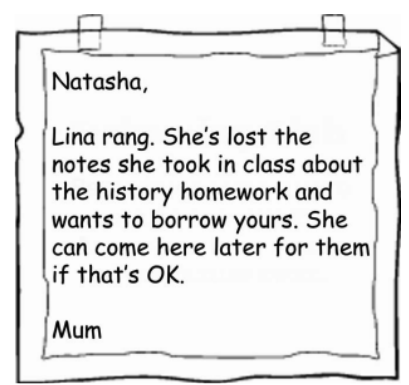

(Cambridge, PET for Schools)

Fig. 5. Creolized texts with simple paralinguistic means. 
More complex paralinguistic means contribute to the transfer of additional information about the situational conditions in which we can encounter a particular fragment of the verbal text. Moreover, before reading the content of the text, the applicant via the graphic design can understand where the action takes place, for example, in a hotel, in an educational institution, in an office, at the airport, at a railway station.

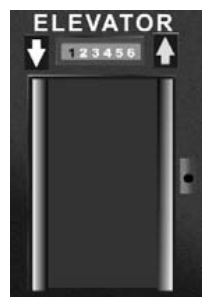

(Edexel, E2, READING)

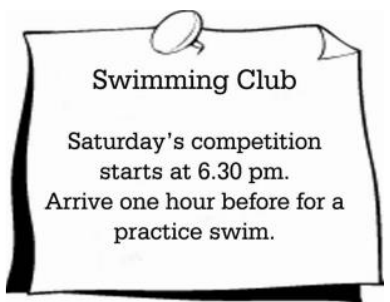

Cambridge, PET for Schools)

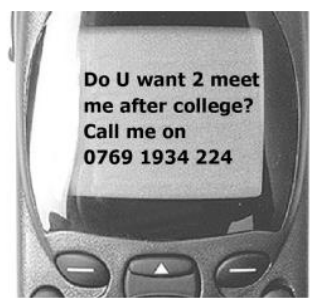

(Edexel, SET, E2, READING)

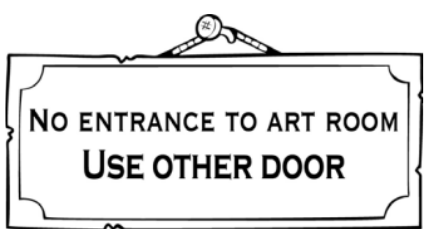

(Cambridge, KET for Schools)

Fig. 6. Creolized texts with complex paralinguistic means.

\subsection{Types of signs and their practical significance in EFL exam creolized texts}

A specific role in fulfilling the already described functional features of the graphic component of creolized texts of English-language examination demo papers (such as Cambridge (Skills for Life), City\&Guilds, Edexel (Skills for Life), Trinity (ESOL Skills for Life)) is assigned to signs (pictograms) from a wide range of spheres of human life, which we have distributed into specific categories. Let us briefly consider them.

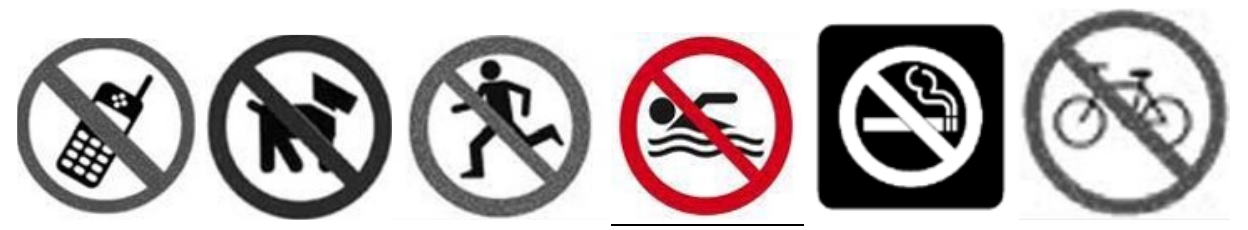

Fig. 7. Signs without verbal component.

1. Service signs: luggage storage, information desk, parenting room, waiting room, lost property, hotel, telephone, swimming pool, beach, gym, dance floor, cloakroom, food point, WC (women's / men's room), medical aid station, post office, library, ticket sales, newspaper sales, waste recycling.

2. Identification marks: disabled person.

3. Special regulation signs: parking place for passenger taxis.

4. Advance direction signs: cycle lane, footpath. 
5. Prohibitory signs: pedestrian circulation, cyclists dismount, smoking, entering with animals or with food, dog walking, cell phones using, driving at a speed higher than specified, parking. path, road works.

6. Warning signs: poisonous substance (skull and bones drawing), crossing a cycle

7. Information signs: train station, stairs, parking, elevator, bus stop, exit.

Such signs can be classified as signals and markers. In demos, the graphic component of the sign is sometimes combined with the verbal component presenting a small-format text:

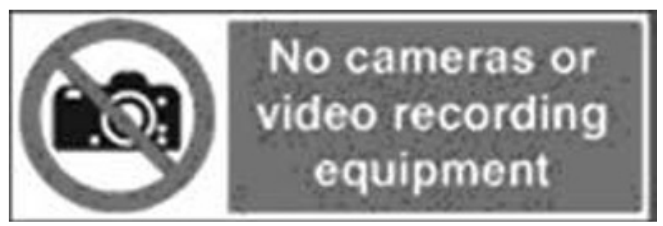

Fig. 8. Sign with verbal component.

(Trinity, SFL, E3)

It is worth mentioning that signs (pictograms), due to the similarity with the depicted object, phenomenon and thanks to the schematic representation of the most recognizable features, carry out the function of transferring socially significant information. Thus, demo versions of examination materials promote applicants' understanding of signs posted in public places (hotels, hospitals, parks, shopping centers, museums, post offices, railway stations, airports, etc), information from labels of medicines and food, road signs. This proves the practical significance of demo paper texts, since the information presented in them tests the ability to navigate in the communicative paradigm of society, and, therefore, graphic images perform informative, illustrative, indicative and directive functions.

\section{Conclusion}

The conducted analysis of the core characteristics of demo paper texts of certified Englishlanguage examinations reveals the widespread use of minitexts with full and partial creolization, and signs (or pictograms). We have stated the special role of combination of verbal and non-verbal elements and of paralinguistic means in forming creolized text space of EFL exams.

In demo papers of international certified exams in English, the output generation of communicative language and non-language means performs various functions, such as: introductory, informative, descriptive, expressive, social, and organizational. Signs also have their special functions, for example, directive, indicative, and illustrative. The analysis of paralinguistic means of creolized texts allows specifying such functions typical for them as attractive, aesthetic, and semantic. Fulfilling all these functions, creolized texts facilitate the perception of the text content and the successful completion of the examination task.

The study lets us conclude that creolized texts of online examination papers of elementary English proficiency have the highest linguo-pragmatic potential, since they contain a plenty of graphic images and a wide variety of paralinguistic means. The functions performed by the graphic component are semantic, attractive, expressive, aesthetic, introductory and informative. This allows perceiving the main and additional content of examination tasks in an easy and adapted way.

However, graphic means do not guarantee successful completion of the examination task, for they are inextricably linked with the verbal component, and often deliberately contradict each other. On the contrary, at more advanced levels of English proficiency, we see the 
superiority of the verbal component over graphic images, with the exception of diagrams and graphs, as the skill of working with sub-content and conceptual information becomes a priority.

As we see, in demo papers of international English-language online examinations the usage of creolized texts is becoming frequent and natural. Although exam compilers adhere to the academic design, they apply bright colorful tones, various illustrations, non-verbal and paralinguistic means. This indicates a high linguo-pragmatic potential of the creolized text space of the English-language academic discourse.

\section{Acknowledgments}

This paper was financially supported by the Russian Foundation for Basic Research, grant No. 20-012-22046.

\section{References}

1. P. Ernst, Pragmalinguistik: Grundlagen, Anwendungen, Probleme. Berlin: Walter de Gruyter (2002)

2. T.S. Samokhina, Cultures and professional communication in standard situation: Difference in communicative behaviour, in Professional Discourse \& Communication, 1(1), pp. 99-110 (2019) (in Russian)

3. T.A. Van Dijk, Critical discourse analysis, in D. Tannen, H. Hamilton, D. Schiffrin (eds.), Handbook of Discourse Analysis. Second Edition. 2 volumes, Chichester: Wiley Blackwell, 1, pp. 466-485 (2015)

4. E.V. Ponomarenko, Functional properties of English discourse in terms of linguosynergetics, in SGEM International Multidisciplinary Scientific Conference on Social Sciences and Arts, 1-3, pp. 355-362 (2016)

5. V.D. Shevchenko, Introduction to the theory of interference of discourses. Samara: SamGUPS (2008) (in Russian)

6. D.S. Khramchenko, Intertextuality and business English discourse: Teaching in harmony with functional linguistic theory, in INTED2017. 11 $1^{\text {th }}$ International Technology, Education and Development Conference. Conference Proceedings, IATED Academy, pp. 1874-1877 (2017)

7. D. Crystal, Language and the Internet. Cambridge University Press (2004)

8. T. Kust, University discourse in computer-mediated communication: Philosophical, sociological and cultural grounds for linguistic description, in Procedia - Social and Behavioral Sciences, Elsevier, 166, pp. 409-414 (2015)

9. A.A. Kharkovskaya, E.V. Ponomarenko, A.V. Radyuk, Minitexts in modern educational discourse: Functions and trends, in Training, Language and Culture, 1(1), pp. 62-76 (2017)

10. I. Platonova, E. Tarasova, A. Golubinskaya, Creolized text as a form of modern educational discourse, in Procedia - Social and Behavioral Sciences, Elsevier, 214, pp. 788-796 (2015)

11. R. Price, Créolisation, creolization, and créolité, in Small Axe, 21, pp. 211-219 (2017)

12. N. Oprishch, O. Ogareva, Teaching English by means of advertising creolized texts, in INTED2020 Proceedings, pp. 8014-8018 (2020)

13. R. Patterson, A. Weideman, The typicality of academic discourse and its relevance for constructs of academic literacy, in Journal for Language Teaching, 47(1), pp. 107-123 (2013)

14. J. Flowerdew, Discourse in English language education. Oxon: Routledge (2013) 
15. J. Flowerdew, Introduction: approaches to the analysis of academic discourse in English, in J. Flowerdew (eds.), Academic discourse, Edinburgh Gate, Longman, pp. 21-39 (2002)

16. L. Salvato, An interdisciplinary approach to texts as a model for a truthful approach to reality, in Procedia - Social and Behavioral Sciences, Elsevier, 174, 2875-2881 (2015) 